The interest of self-help groups in social sharing and narrative construction: a french example in incest trauma.

Mariel PIETRI, Marie-Anaïs ROQUES and Evelyne BOUTEYRE**

* Laboratory of Clinical Psycholoy, Clinical Psychopathology and Psychoanalysis, (EA 3278), Aix-Marseille University 29, avenue Robert Schuman, 13621, Aix-en-provence, France. 


\section{SELF-HELP GROUPS AND INCEST TRAUMA}

\section{Introduction}

Incest is considered as fundamentally forbidden. Even if it has long been ignored by society, nowadays incest draws the attention of public authorities and can be seen as "reprehensible and judicially penalized acts" and as "a violation of human rights" (Fassin \& Bourdelais, 2005, p.7). From a penal point of view, France has recently (March $\left.14^{\text {th }}, 2016\right)$ inserted the word "incest" in its Penal Code. This penal code defines incest as rape and sexual assaults committed within the family by an ascendant, a brother, a sister or anyone having a legal or de facto control over a minor (article 222-31-1 of the penal code).

Despite the growing legitimacy in the recognition of incest, there is little European scientific literature on the consequences and the care for incest victims. However, incest is a traumatic experience for victims as it affects them in a very intimate level and causes significant long term as well as short term damages (Kendall-Tackett, Williams and Finkelhor 1993).

According to Pedinielli and Mariage (2015), trauma is defined as a "shock on the psyche by an outside psychological agent leading to temporary or durable psychological distress". In other words it is an emotional outpour caused by an unexpected event. Marcelli (2014) describes trauma as a "anti-memory trace", an event that threatens the victims' continuity of existence and that can hinder the creation of a narrative out of this traumatic experience. This can explain the common difficulty for victims to talk about the incest they experienced.

Incest differs from any other type of trauma as it requires victims to deal with the following contradiction: they are supposed to live in a loving, caring and trustworthy family unit that includes a family member that commits sexual abuse (Dussy, 2015). Incest affects victims both psychologically and somatically. Victims often show dissociative disorders such as depersonalization and derealization: memory, conscience or identity disruptions. They have the 


\section{SELF-HELP GROUPS AND INCEST TRAUMA}

feeling of being detached from themselves, of becoming an observer of their own mental functioning (Pedinielli and Mariage, 2015, p. 46).

By treating victims as objects, incest prevents them from their subjectivity; the abuse can dispossesse the victims of their human qualities (Honneth, 2007) and remove their psychical workings. As their analytical skills are disturbed, a lot of victims are unable to give meaning and assimilate the traumatic experience. Some Victims would not able to appropriate the experience; incest affects the victim at a very intimate level and leads to a fractured identity that deconstructs subjective and intersubjective relationships (Garnier, 2015). Thus, it seems hard to invest in positive relationships with others. Consequently, most victims isolate themselves from the rest of the world, thus creating an obstacle to the therapeutic alliance.

Sexual abuse affects victims at a very intimate level, making it very hard for them to confess as they usually feel ashamed or guilty. According to Pennebaker (1989), remaining silent is a stressful experience. However, disclosing the abuse can also have a negative impact on victims. According to Kelly (2002), disclosing the abuse can lead to a rejection from the victims' social group. To avoid this risk and to preserve the bond with their relatives, victims often remain silent. The need to belong to a social group takes precedence over the abuse disclosure. Rimé (2005) explains that keeping this emotionally charged information secret contributes to the victims' isolation. Consequently, the victims' willingness to stay silent in order to stay in the social group ironically contributes to their isolation. The composition of the social group will play a capital part in the victims' isolation process.

However, keeping the abuse secret creates a state of stress for victims and requires a cognitive effort. Furthermore, active inhibition of the verbalization of emotions has an adverse effect on the victims' physical health and can provoke autonomic disturbance and immunodepression (Temoshok, 1983; Larson and Chastain, 1990; Pennebaker, 1997). On the other hand, this same fundamental need of belonging could constitute an incentive to disclosure secret information to 


\section{SELF-HELP GROUPS AND INCEST TRAUMA}

consolidate social relationships (Kelly, 2002). Therefore, victims are confronted with an absurd paradox: disclose the abuse or keep silent.

In the face of the suffering caused by incest, numerous therapeutic options are set up to provide psychological support for the victims. Previous research has shown the efficiency of group therapy (Dorrepaal and coll., 2010; Zlotnick and coll., 1997). Compared to individual therapy sessions, group therapy is widely used to support incest victims (Tourigny and Hébert, 2007). Group therapy differs from individual therapy in numerous characteristics, in particular what Kivlighan and Holmes (2004) call the universality concept. It can be defined as the perception of one member that the other members of the group share the same problems and the same feelings. Group therapy offers the members' a feeling of universality, that is, a chance to talk about the abuse with people who potentially, feel the same (Avinger and Jones, 2007). Group therapy offers not only a place where victims can build positive relationships with others but also a place where the feeling of stigmatization is reduced and the feeling of being different attenuated.

Along with therapeutic groups, other types of support groups are expanding called self-help groups. Because no professional therapist (psychologist or psychiatrist) attends, these self-help groups have no therapeutic goal per se; however, members' testimonies suggest that such groups may have some therapeutic effects. Within fifty years, self-help groups have developed worldwide as an alternative type of care complementary to conventional therapies (Borkman, 1999; Munn-Giddings and McVicar, 2006). They are organized by members who all share a same condition. These groups provide a place where they can share and talk about their emotions and their experience. The aim of self-help groups is to offer a moment of conviviality and mutual listening that will provide social support. Even if the number of participants or the thematic of the session can vary from a self-help group to another, some rules are common to all types of group: confidentiality, discretion, freedom of expression, non-judgmental attitude, physical and 


\section{SELF-HELP GROUPS AND INCEST TRAUMA}

verbal non-violence, free flow of ideas by words (Guichardon, 2006). Reciprocity and equality are the keystones of self-helps groups; members tell about they experience and receive emotional and social support as well as experiential knowledge through the testimonies of others (Munn-Giddings and McVicar 2006). Experiential knowledge differs from knowledge acquired through observation or through information transmitted by other or by books (Elsdon and al. 2000). Self-help groups are frequently designed for trauma victims as it allows the members to share about the same type of event. According to Ranchin (2015, p.99), self-help groups provide a personal discovery through the discovery of others.

In this context, by offering an environment for talking and listening, self-help groups provide additional support to conventional individual therapies where victims can tell about their traumatic experience. According to Fisher $(1984,1989)$, it is in the light of the narration that the people give the meaning of the world they live in. As for Bruner $(1987 ; 1991)$, narration is a form of thought and a form of discourse in which we understand and we express our personal experience. Hearing the difficulties faced by others enables members to talk about his own challenges and to differentiate from them (Gihr Bouclet, 2012). In this, self-help groups function as a subjectification space. Subjectivity is defined by Beneviste (1966) as the ability for the speaker to adopt a proactive position through enunciation, discursive productions and through the lexem's semantic structure (Bertrant, 2005). According to Ricoeur (1990), subjectivity would be based on the language and would be the condition for the construction of a psychic space.

\section{Objective:}

The aim of this study is to assess the effects of a self-help group on the discourse of incest victims. The main objective is to show that sharing a traumatic experience and talking about its main consequences provides the victim with a space encouraging émotion's verbalization and 


\section{SELF-HELP GROUPS AND INCEST TRAUMA}

psychical working out. In this way, self-help groups as well as therapeutic groups would offer protection and identification anaclisis, allowing victims to feel considered as full-fledged individuals.

\section{Methodology}

\section{Population and research protocol}

This research was conducted in collaboration with the Association Internationale des Victimes de l'Inceste (AIVI, international association for incest victims) in the French city of Marseille. This association was created in 2002 in France by and for incest victims. In 2002, AIVI created thematic self-help groups in six French cities. In 2017, seven active groups offer, each month, a space for dialogue and listening where incest victims can talk about their traumatic experience.

The AIVI group is quite unique in having such a formalized protocol and system for operation. The self-help group organized in Marseille welcomes fifteen participants each month to talk about themes related to incest. Each session consists of two distinct parts, the first one is intended for the members to express representations and feelings associated with the theme (ex: Have you ever felt or do you still feel the need for justice? / Do you sometimes feel angry and how do you express this anger?) and the second one is aimed towards coming up with actions and solutions (ex: What solutions have you found to cover this need for justice? What means have you adopted to deal with your feeling of anger?).

Each participant has three minutes to express himself and to share his experience. The clinical material is composed of transcribed audio recording of Marseille's self-help group. The informed consent of all the participants was obtained.

The discourse of 9 participants was used, 6 women and 3 men with a mean age 40 years and 6 months (s.d. 9.375) 


\section{SELF-HELP GROUPS AND INCEST TRAUMA}

First, we compared the evolution of the participants' discourse between September 2015 and June 2016. Then, we compared the evolution of the discourse from year to year on the same theme; the theme of justice was chosen (March 2016 and November 2016) for which the discourse of 5 participants was used. The theme of anger was also picked (October 2015 and December 2016) for which the discourse of 4 participants was used. These two themes were chosen because the same participants were present from year to year.

\section{Data Processing}

In the first instance, a semantic analysis was conducted using Tropes software (Zoom VF8.4) (Ghiglione, Landré, Bromberg and Molette, 1998) and EMOTAIX (Piolat and Bannour, 2009). Tropes software provides a quantitative analysis of discourses, by splitting and organizing them into categories according to the lexicon used by the participants. EMOTAIX provides an insight into the emotional tone of the discourse.

An analysis was carried out to inquire about the style of the discourse (discourse construction, implication of the person through the use of the personal pronoun "I"). A grammatical breakdown was effected to distinguish the verbs from the connectors, the modalities and the adjectives.

To evaluate the emotional tone of the discourse, EMOTAIX finds in the body of the text the frequency of occurrence of emotions as well as their positive valence (emotions related to goodwill, well-being and nerve) or their negative valence (emotions related to aggression, suffering and anxiety).

Three features were processed:

- The construction of the discourse: the style of the discourse (argumentative, declaratory and descriptive) refers to the global structure of the text. It informs the reader about the participant's form of expression (how is the message conveyed? How the participant's 


\section{SELF-HELP GROUPS AND INCEST TRAUMA}

experience is transmitted to the rest of the group?). The use of personal pronouns informs about the way the participant is actively and personally involved in his discourse.

- The discourse features: the word classes used by the participants provide information about the grammatical structure of the text by focusing on the nature of the verbs (stative verbs or factive verbs), on the connectors (condition, cause, opposition, addition), and on the adjectives (subjective, objective)

- Emotional tone: the prevalence of positive and negative emotions in the text is calculated.

Statistic analysis were then conducted on the results of the quantitative analysis of discourse using SPSS ${ }^{\circledR}$. The results are expressed in percentage; Pearson's chi-squared test was used to detect a trend and to measure the evolution of the three specific features over time.

\section{Results: emotional and lexical analysis}

\section{a. Lexical analysis of the discourse}

The results show that every month, the majority of the participants express themselves using an argumentative style of discourse. It is distinguished by the use of words reflecting an argumentative approach such as modalities (intensity modalities: "a lot of"; negation modalities: "never") and connectors (opposition connectors: "but"; comparison connectors: "like").

The argumentative style of discourse reveals an attempt by the speaker to convince the interlocutor. Furthermore, according to Tropes software, the participants' discourse is characterized by the use of the personal pronoun « $\mathrm{I} »$, revealing their implication and their active position. 


\section{SELF-HELP GROUPS AND INCEST TRAUMA}

Participants mostly and significantly $(\mathrm{p}<.001)$ use factive verbs $(41.5 \%)$ that express the action: "I try to work on that, I managed to fit in" and stative verbs (36.7\%) that suggest a state (to be, to feel, to become) or a possession ("to belong", "to have"): "I don 't feel anything anymore".

Furthermore, participants mostly and significantly $(\mathrm{p}<.001)$ use addition connectors $(39.9 \%)$, causal connectors $(25 \%)$, opposition connectors $(16.2 \%)$ and time connectors $(14.5 \%)$. These results highlight the argumentative structure of the discourse through the enumeration of facts (action and time related, ex: "and", "then") and the presence of reasoning: "We share and suddenly all is closed and the clash starts".

Cause connectors are used to build and support a piece of reasoning ("because", "given that", "so", "thus"): "I stopped medical monitoring with my psychiatrist because he wanted to prescribe medicines". Opposition connectors are used to argue opposite points ("anyway", "even if", "in contrast"): "Even if it is not a taboo anymore, I find it hard to talk about it".

Time connectors are used to situate the action in time ("when", "after", "once", "since"): "When I was little, I had memory losses".

The results show that lots of intensity modalities (34.9\%) and negation modalities (21.8\%) are used within the discourse of the participants. These types of modalities express a dramatization of the discourse, highlighting the consequence of an element or increasing its intensity ("not", “no", "never”, "nobody”): "I have lots of trouble sleeping, I somatize a lot"; "no, I don't have any memories of my childhood".

Time modalities are also frequently used (15.64\%) and provide indications on the time of the action ("after", "at the same time", "since", "as soon as"): "Since adolescence, I have always been in this hyper vigilant mode". 


\section{SELF-HELP GROUPS AND INCEST TRAUMA}

Finally, subjective adjectives are proportionally and significantly $(\mathrm{p}<.001)$ prevalent compared to the others $(51 \%)$. They provide a value judgment or highlight an emotional dimension to the discourse ("unpleasant", "sad", "positive”, “confident”): “incest also has positive consequences".

\section{b. Evolution of the frequency of use of the words categories}

Wilcoxon Test was used to compare the prevalence of the discourse's characteristics features over time (Table 1). Results bring out the participant's implication when talking about his problematic.

Firstly, between September 2015 and June 2016, results show a significant increase (p <.001) in the use of stative verbs, intensity and time modalities as well as condition connectors. During the same period of time, results show a decrease of the use of manner modalities. Secondly, between September 2015 and January 2016 a decrease of the use of affirmative modalities was observed. Manner modalities qualify the discourse (ex: "simply", "directly", "anyway"). For example: "I don't know how it went". On the other hand, affirmative modalities demonstrates the speaker's willingness to affirm and support his message ("really", "exactly", "absolutely", “obviously"). For example: "I have to maintain control over absolutely everything".

Finally, results show an increase in the use of subjective adjectives in January 2016 as well as a decrease in the use of the personal pronoun "I" and an increase in the use of the personal pronoun "we" in June 2016.

- The theme of anger: comparison between 2015's and 2016's sessions.

Compared to 2015, the prevalence of use of factive verbs and subjective adjectives is significantly higher in the participants' discourse in 2016. Results also show a decrease in the use of numeric adjectives and in the use of cause, addition and opposition connectors in 2016. 


\section{SELF-HELP GROUPS AND INCEST TRAUMA}

Lastly, results underscore an increase in the use of personal pronouns "I" and "we" between 2015 and 2016.

- The theme of justice: comparison between 2015's and 2016's sessions

Analyses bring to light an increase in the use of factive verbs, objective adjectives and intensity modalities in 2016. However, results show a decrease in the use of opposition connectors ( $p$ $<.001)$

\section{c. Emotional tone comparison between 2015 and 2016}

Pearson's chi-squared test was use to compare the frequency of occurrence of emotions between 2015 and 2016 (Table 2).

Results show a significant decrease of negative emotions and a significant increase of positive emotions between September 2015 and June 2016 ( $p<.01)$.

\section{- The theme of anger:}

Regarding the theme of anger, results show an increase in the use of emotional vocabulary related to well-being and anxiety as well as a significant decrease in the use of emotions related to suffering and aggression $(\mathrm{p}<.05)$ between 2015 and 2016.

- $\quad$ The theme of justice

Regarding the theme of justice, results show a significant decrease in the use of words related to negative emotions as well as an increase in the use of positive emotional vocabulary $(\mathrm{p}<.01)$ between 2015 and 2016).

Specifically, participants express more emotions related to well-being and express less emotions related to aggression $(\mathrm{p}<.001)$. 


\section{SELF-HELP GROUPS AND INCEST TRAUMA}

\section{Discussion}

The findings demonstrate that the participants tend to produce an argumentative discourse, underlining their implication and their active role. The participants give their opinion, they express themselves (Blanchet, 2004). Through the use of language processes, participants express their own truth; however, beyond this will to transmit, participants undertake an approach involving self-reflection on their personal history.

Furthermore, results show that participants mostly use stative and factive verbs. These two categories of verbs are opposed to one another. Stative verbs express a continuous or persistent state, a possession or an abstract relationship whereas factive verbs express an action. This result demonstrates the opposition between the continuity of mental representation related to the theme of the group and the punctual action implemented regarding the theme. As already said, each session consists of two distinct parts: the first one is intended for the members' representations associated with the theme and the second one aimed for the actions and solutions found. The occurrence of stative and factive verbs reveals the member's behavioral commitment and his ability to think as an actor of his own existence; it expresses the member's ability to take decision and to take action.

The frequency of use of intensity and negation modalities outlines the traumatic impact of incest. These modalities are associated with addition connectors that express a will to tell about their personal history. They are also associated with opposition and cause connectors that express a will to argue, to balance and to give meaning to the discourse (Ghiglione and al. 1998).

The use of subjective adjectives highlight the subjective aspect of the language as the speaker is not neutral when talking about his life story (Yeinik, 2005). Even if psychological trauma impedes the victim's ability to create a narrative out of their lives (Marcelli, 2014), the 


\section{SELF-HELP GROUPS AND INCEST TRAUMA}

recurrence of additive connectors reveals a desire to do so. The frequency of use of subjective adjectives and of the pronoun "I" show an attempt to appropriate their personal history through narration.

The trauma elaboration as well as the subjectification process can however be questioned; the frequency of use of time modalities characterize a factual narrative why is a key feature of the flashbacks found in the Post-Traumatic Stress Disorder. Time references outline the participants' need to distance themselves from the abuse and their attempt to control However, when facing a psychological trauma, the victim's psyche is flabbergasted and temporal references become fuzzy; results show that this is not the case for the participants of this research. According to Ricoeur (1990) and Ezzy (1998), temporality ensures continuity and therefore helps for the creation of a unique identity. The recurrence of temporal indicators, time connectors and time modalities creates continuity and demonstrates the participants' interest to tshare their personal history. Situating the abuse in time is also important for the participants as it expresses the impact of time on their experience. By using enunciation process, their personal history appears to be a part of what Marcelli (2014) calls "existential continuity".

Analyses reveal an evolution in the prevalence of use of certain word categories as well as in the emotional tone over the months. Results show an increase of the prevalence of use of stative verbs, of intensity and time modalities, of condition connectors and a decrease of the prevalence of affirmative and manner modalities. This reflects the impact of the abuse as a deeply held and life-altering experience and the development of an argument about it.

Regarding the two themes picked for this article, participants use more factive verbs and objective adjectives. Furthermore, results show a decrease in the use of opposition, cause and addition connectors. This reflects the participants' ability to step back and to ease the suffering toward the theme picked. This interpretation is underlined by the evolution of the participants' 


\section{SELF-HELP GROUPS AND INCEST TRAUMA}

emotional tone. For the two themes, results show an increase in the use of emotional vocabulary related to well-being as well as a decrease of the use vocabulary related to aggression.

Through support, listening and feeling of belonging, self-help groups create an environment of trust and security that encourages processes. According to Zech and Rimé's study (2005), compared to participants' in a control condition, participants who were asked to verbalize their emotions expressed more psychological benefits such as: relief, cognitive (ex: emotional recovery) and interpersonal benefits (ex: the feeling to being understood). Thus, socio affective benefits ensuing the emotional social sharing contribute to relieve the negative emotional impact due to verbalization. However, this relief is not maintained over time (Rimé, 2009). The immediate relief would explain the members' tendency to repeat the social sharing each month. Therefore, participants benefit from a short-term emotional relief provided by socio affective dynamics through social sharing. Over the months, this emotional relief can be captured in the group's participants. Overall, results show an increase in the use of positive emotional vocabulary over time, as well as a decrease in the use of negative emotional vocabulary.

These results can be balanced; after experiencing a negative emotional experience, the popular belief suggests the discharging power of speaking: verbalizing its feelings would play a cathartic role that would help the victim to recover emotionally. This belief would be consistent with the repetitive and recurring nature of the emotional social sharing. However, the cathartic role of emotional social sharing has never been confirmed scientifically: positive effects related to the emotional distress are weighted by situational factors as well as interpersonal and intrapersonal factors (Kennedy-Moore and Watson, 1999). Furthermore, to make our data generalizable it would be valuable to conduct the same research with a bigger sample of participants. But this study draws attention to the importance and role of self-hellp groups outside professional contexts and help us to understand the process of verbal communication in self-help group and on how to deal with the traumatic experience. The 


\section{SELF-HELP GROUPS AND INCEST TRAUMA}

important aspect of this group is that it is structured and has distinct themes. One future study would be to compare the results of this kind of structured and systematic self-help group with an online group that is open and unstructured. To continue this research from an experimental perspective, resilience, social support and psychological distress evaluations are currently in progress.

\section{Conclusion:}

The aim of this research was to explore the impact of emotional social sharing on the psychical workings of incest victims. Results show subjectification features within the participants' discourse. This characterizes an attempt to appropriate the traumatic experience as "language activity is subjective" (Kerbrat-Orecchioni, 1980 cited in Yeinik, 2005) and as the participant cannot be neutral about its personal history. Results support the hypothesis that self-help group would foster verbalization and sharing processes as well as psychical working out processes. By telling themselves and the other members their personal history, participants find meaning. Self-help groups would offer the participants what Marcelli (2014) calls "a narrative reflexivity" by maintaining the illusion of an existential continuity.

\section{References:}

- Benveniste, E. (1966) Problèmes de linguistique générale 1. Paris : Gallimard.

- Bertrand, M. (2005) 'Qu'est-ce que la subjectivation?', Le carnet psy 1 (96): 24-27

- Blanchet, A. (2004) Dire et faire dire. L'entretien. Paris : Armand Colin.

- Bruner. J, (1987) 'Life as Narrative', Social Research,54 (1): 11-32.

- Bruner, J. (1991) 'The Narrative Construction of reality', Critical Inquiry: 1-21.

- De Becker, E., and Maertens, M.A. (2015) 'Le devenir de l'enfant victime de maltraitance sexuelle', Annales Medico-psychologiques 173 (9): 805-814. 


\section{SELF-HELP GROUPS AND INCEST TRAUMA}

- Dorrepaal, E., Thomaes, K., Smit, J.H., van Balkom, A.J.L.M., van Dyck, R. Veltman, D.J., and al (2010) 'Stabilizing group treatment for complex posttraumatic stress disorder related to childhood abuse based on psycho-education and cognitive behavioral therapy: A pilot study', Child Abuse \& Neglect 34 : 284-288.

- Ezzy, D. (1998) 'Theorizing Narrative Identity: Symbolic Interactionism and Hermeneutic', The Sociological Quarterly 39 (2): 239-252.

Fallery B et Rodhain F (2007) Quatre approches pour l'analyse de données textuelles : lexicale, linguistique, cognitive et thématique. 16éme ConférenceInternationale de Management Stratégique, Montréal, 6-9 juin, 2007.

- Fassin, D. and Bourdelais, P. (2005) Les constructions de l'intolérable. Études d'anthropologie et d'histoire sur les frontières de l'espace moral. Paris : La Découverte.

- Finkenauer, C. and Rimé, B. (1998) 'Socially shared emotional experiences vs. emotional experiences kept secret: Differential characteristics and consequences', Journal of Social and Clinical Psychology 17: 295-318.

- Fisher, W.R. (1989) 'Clarifying the narrative paradigm', Communication Monographs, 56: $55-58$.

- Fisher, W.R. (1984) 'Narration as a Human Communication Paradigm: The Case of the Public Moral Argument', Communication Monographs 51: 1-22.

- Garnier, S. (2015) Clinique des violences sexuelles : du psychotraumatisme à la prise en charge. In de Tyckey C (Ed.), Violence subie et résilience . Toulouse : Eres? Pp. 26-52.

- Ghiglione, R., Landré, A., Bromberg, M. and Molette, P. (1998) L'analyse automatique des contenus. Paris : Dunod.

- Gihr Bouclet ,C. (2012) 'Le groupe de parole, un espace de reconnaissance’, Gestalt 41: 113-126. 


\section{SELF-HELP GROUPS AND INCEST TRAUMA}

- Honneth, A. (2007) La réification. Petit traité de théorie critique. Paris : Gallimard Kelly A (2002) The Psychology of Secrets. New York: Plenum Publishers

- Kendall-Tackett, K.A., Williams, L.M., and Finkelhor, D. (1993) 'Impact of sexual abuse on children: A review and synthesis of recent empirical studies', Psychological Bulletin, 113 (1): 164-180.

- Kennedy-Moore, E., and Watson, J.C. (1999) Expressing emotion: Myths, realities, and therapeutic strategies. New York: Guilford.

- Kivlighan, D.M. and Holmes, S.E. (2004) 'The importance of therapeutic factors: A typology of therapeutic factors studies' In DeLucia-Waack, J.L., Gerrity, D.A., Kalodner, C.R. and Riva, M.T. (Eds.) Handbook of group counselling and psychotherapy. Thousand Oaks, CA: Sage Publications, pp 23-26.

- Larson, D.G. and Chastain RL (1990) 'Self-concealment: Conceptualization, measurement, and health implications', Journal of Social and Clinical Psychology 9: $439-455$.

- Marcelli, D. (2014) 'La “trace anti-mnésique”. Hypothèse sur le traumatisme psychique chez l'enfant', L'information psychiatrique 90 (6): 439-446.

- Pedinielli, J.L. and Mariage, A. (2015) Psychopathologie du traumatisme. Paris : Armand Colin.

- Pennebaker, J.W. (1997) Opening up: the healing power of expressing emotion. New York: Guilford

- Pennebaker, J.W. (1989) 'Confession, inhibition, and disease' in: Berkowitz, L. (ed.) Advances in Experimental Social Psychology, vol. 22. New York: Academic Press, pp: $211-244$. 


\section{SELF-HELP GROUPS AND INCEST TRAUMA}

- Piolat, A. and Bannour, R. (2009) 'EMOTAIX : un scénario de Tropes pour l'identification automatisée du lexique émotionnel et affectif', L'année psychologique 109: 655-698.

- Ranchin, B. (2015)' Là, dans le groupe, j'ai appuyé sur la touche de l'intelligence. Les effets du travail en groupe. L'exemple de groupes de parole d'hommes auteurs de violences conjugales', Empan 99 (3): 98-104.

- Ricœur, P. (1990). Soi-même comme un autre. Paris : Edition du Seuil.

- Rimé, B. (2005) Le partage social des émotions. Paris: Presses Universitaires de France.

- Rimé, B. (2009) Emotion elicits the social sharing of emotion: Theory and empirical review. Emotion Review 1 (1): 60-85.

- Temoshok, L.R. (1983)'Emotion, Adaptation, and disease: A multidimensional theory' in Temoshok, L., Dyke, C.V. and Segans, L.S. (Eds.) Emotions in health and Illness . New York: Grune \& Stratton, pp, 207-233

- Tourigny, M. and Hébert, M. (2007) 'Efficacy of an open group therapy for sexually abused adolescent girls', Victims and Violence 22 (3): 334-349.

- Yeinik, T. (2005) 'L'entretien clinique de recherche en sciences de l'éducation', Recherche et formation 50: 133-146.

- Zech, E. and Rimé, B. (2005). Is talking about an emotional experience helpful? Effects on emotional recovery and perceived benefits. Clinical Psychology and Psychotherapy 12: $270-287$. 